\title{
Characteristics and Performances of a Nanostructured Material for Passive Samplers of Gaseous Hg
}

\author{
Joshua Avossa ${ }^{1,2}$, Fabrizio De Cesare ${ }^{1,3} \oplus^{\circledR}$, Paolo Papa ${ }^{1}\left(\mathbb{D}\right.$, Emiliano Zampetti ${ }^{1}{ }^{\circledR}$, \\ Andrea Bearzotti ${ }^{1}\left(\mathbb{D}\right.$, Marcello Marelli ${ }^{4}\left(\mathbb{D}\right.$, Nicola Pirrone ${ }^{5}$ and Antonella Macagnano ${ }^{1,3, *(\mathbb{D})}$ \\ 1 Institute of Atmospheric Pollution Research-National Research Council, Research Area of Rome 1, Via \\ Salaria km 23,600, Monterotondo, 00016 Rome, Italy; joshua.avossa@empa.ch (J.A.); \\ decesare@unitus.it (F.D.C.); p.papa@iia.cnr.it (P.P.); e.zampetti@iia.cnr.it (E.Z.); a.bearzotti@iia.cnr.it (A.B.) \\ 2 Laboratory for Biomimetic Membranes and Textiles, Empa, Swiss Federal Laboratories for Materials Science \\ and Technology, Lerchenfeldstrasse 5, CH-9014 St. Gallen, Switzerland \\ 3 Department of Innovation in Biological Systems, Food and Forestry (DIBAF), Via S. Camillo de Lellis, \\ University of Tuscia, 00100 Viterbo, Italy \\ 4 Institute of Chemical Sciences and Technologies "Giulio Natta" (SCITEC)—National Research Council, c/o \\ Area di Ricerca di Milano 1, Sede Fantoli, Via Fantoli 16/15, 20138 Milano, Italy; marcello.marelli@scitec.cnr.it \\ 5 Institute of Atmospheric Pollution Research-National Research Council, Division of Rende, UNICAL \\ Polifuzionale, 87036 Rende, Italy; pirrone@iia.cnr.it \\ * Correspondence: antonella.macagnano@cnr.it
}

Received: 21 September 2020; Accepted: 21 October 2020; Published: 23 October 2020

check for updates

\begin{abstract}
Passive air samplers (PASs) have been used for mapping gaseous mercury concentration in extensive areas. In this work, an easy-to-use and -prepare gold nanoparticle (NP)-based PAS has been investigated. The PAS is constituted of a microfibrous quartz disk filter impregnated of gold NP photo-growth on $\mathrm{TiO}_{2} \mathrm{NPs}\left(\mathrm{Au} @ \mathrm{TiO}_{2}\right)$ and used as gaseous mercury adsorbing material. The disk was housed in a cylinder glass container and subjected to an axial diffusive sampling. The adsorbed mercury was measured by thermal desorption using a Tekran ${ }^{\circledR}$ instrument. Different amounts of $\mathrm{Au} @ \mathrm{TiO}_{2}$ (ranging between 4.0 and $4.0 \times 10^{-3} \mathrm{mg}$ ) were deposited by drop-casting onto the fibrous substrate and assessed for about 1 year of deployment in outdoor environment with a mercury concentration mean of about $1.24 \pm 0.32 \mathrm{ng} / \mathrm{m}^{3}$ in order to optimize the adsorbing layer. PASs showed a linear relation of the adsorbed mercury as a function of time with a rate of $18.5 \pm 0.4 \mathrm{pg} / \mathrm{day}(\approx 1.5 \%$ of the gaseous concentration per day). However, only the PAS with $4 \mathrm{mg}$ of $\mathrm{Au} @ \mathrm{TiO}_{2}$, provided with a surface density of about $3.26 \times 10^{-2} \mathrm{mg} / \mathrm{mm}^{2}$ and $50 \mu \mathrm{m}$ thick inside the fibrous quartz, kept stability in working, with a constant sampling rate (SR) $\left(0.0138 \pm 0.0005 \mathrm{~m}^{3} /\right.$ day) over an outdoor monitoring experimental campaign of about 1 year. On the other hand, higher sampling rates have been found when PASs were deployed for a few days, making these tools also effective for one-day monitoring. Furthermore, these PASs were used and re-used after each thermal desorption to confirm the chance to reuse such structured layers within their samplers, thus supporting the purpose to design inexpensive, compact and portable air pollutant sampling devices, ideal for assessing both personal and environmental exposures. During the whole deployment, PASs were aided by simultaneous Tekran ${ }^{\circledR}$ measurements.
\end{abstract}

Keywords: gaseous mercury pollution; $\mathrm{Au}-\mathrm{TiO}_{2}$ nanoparticles; passive sampler; axial diffusion; thermal desorption; monitoring campaign

\section{Introduction}

Mercury $(\mathrm{Hg})$ is a persistent bio-accumulative toxic metal [1] existing in many different forms in the environment. It continuously cycles between the atmosphere, soil and ocean changing form 
and stability: when mercury is released into the atmosphere, it can remain there or be transferred to soil or oceans, and eventually return to the atmosphere. Gaseous Elemental Mercury (GEM) is the most stable form of $\mathrm{Hg}$ (abbreviated as $\mathrm{Hg}(0)$ or $\left.\mathrm{Hg}^{0}\right) . \mathrm{Hg}^{0}$ is the most abundant form in ambient air, with a residence time spanning from months until about 1 year [2]. $\mathrm{Hg}^{0}$ can be oxidized in the troposphere [3] forming different divalent species, like $\mathrm{HgCl}_{2}, \mathrm{HgBr}_{2}, \mathrm{HgO}, \mathrm{HgBrOH}$ named Gaseous Oxidized Mercury (GOM) [3-6]. GEM and GOM represent the total amount of gaseous mercury species, and for this reason, they are named as Total Gaseous Mercury (TGM). Mercury chemical species adsorbed on particulate matter form the so-called Particulate Bound Mercury (PBM) [7]. Compared to GEM life, GOM and PBM have a shorter lifetime [8,9] and can be deposited on the ground (by wet and dry deposition) and dissolved in water [10]. Hence, it usually enters the environment near its source. Thus, controlling gaseous $\mathrm{Hg}(\mathrm{II})$ and $\mathrm{Hg}(0)$ emissions may have local and global benefits, respectively. Finally, all the mercury species dissolved in water will be subjected to oxidation or reduction reactions [11]. Thus the behavior of mercury in the environment looks complicated: mercury deposited as $\mathrm{Hg}(\mathrm{II})$ can come back to the atmosphere as $\mathrm{Hg}(0)$.

Additionally, $\mathrm{Hg}(0)$ can react (oxidize) to form $\mathrm{Hg}$ (II) in the atmosphere, and $\mathrm{Hg}$ (II) can then reduce back to $\mathrm{Hg}(0)$. In other words, mercury can continuously change its form.

Correlating $\mathrm{Hg}$ concentration and its forms to the sources of emission is of paramount importance to delineate its transport and fate in the environment in order to identify and, eventually, reduce anthropogenic sources. The adoption of both advanced sensors [12-14] and analytical devices [15-17] in monitoring mercury and its forms on a global scale is one of the key requirements within international programs devoted to the earth observation. Indeed, mercury has been regulated by international agreements, national agencies and recently on a global scale through the United Nations Environmental Program (UNEP)—Minamata Convention [18-21]. Since 2010, to create an international network capable of providing accurate measurements of $\mathrm{Hg}$ on a global scale, a European program called the Global Mercury Observation System (GMOS) has been financed [22] with the dual aim to protect the ecosystems and human health from anthropogenic emissions and to control and measure the release of mercury species in the air.

Passive air sampling is an additional common strategy used to collect and measure gaseous Hg. Even though passive air samplers (PASs) are not real-time monitoring systems, they overcome the limitations of other approaches like active monitoring systems, since they enable the simultaneous spatial $\mathrm{Hg}$ measurements in different areas, thus creating a map of the $\mathrm{Hg}$ concentration surrounding the sources of emission [23]. PASs are widely used for environmental monitoring of mercury and other pollutants in the air. The features of passive sampling are related to the principles of green analytical procedures, typically characterized by decreasing sample treatment steps and energy-saving and in situ measurements [24]. On the contrary, a typical drawback of PASs is the coarser temporal resolution consequent to the extended exposure time required to collect a detectable amount of mercury that generally spans from weeks to months. Furthermore, the uptake profiles and sampling rate (SR) of the adsorbed chemicals need to be determined from previous calibration studies, where analyte concentrations collected on the passive sampler are compared with concentrations detected by active sampling methods, where the sampled volume is known [25].

Usually, the adsorbing material in a PAS is located inside a container protected by a membrane on a disk-like geometry or column geometry surrounded by a cylindrical diffusive barrier. The latter samplers, Radiello ${ }^{\circledR}$, are the most known commercial radial-type tools that are characterized by higher adsorbing surface resulting in an increased sampling rate (SR) [26]; the con is that the uptake depends on the wind conditions, thus reducing data reliability of outdoor monitoring [27]. McLagan et al. overcame this limitation by designing a PAS constituted of a Radiello ${ }^{\circledR}$ sampler placed into a protective shield for outdoor deployment [28]. Differently, in the case of axial-type PASs, pollutants diffuse along the container path until reaching the adsorbing material (tube-type passive). The SR of axial-type samplers can be set by adjusting the length of the diffusive path inside the container. Therefore, for 
indoor deployment (no wind), short diffusive paths are more suitable than long paths, which are used for outdoor exposure.

Activated carbon and sulfur-impregnated carbon [22,28-31] are the most common and commercialized type of adsorbing material for TGM due to the low cost and the relatively low amount of material used $(\approx 1 \mathrm{~g})$. However, since the analytical method to measure the adsorbed mercury is digestion, these adsorbing materials are disposable. Samplers based on gold materials in thin films [12,31,32] or nanoparticles (NPs) [33-37] have been developed and used in both active [12,38] and passive mercury samplers [31,33,35-37] for TGM monitoring. The high affinity between mercury and gold enables the uptake of little concentrations of mercury species upon amalgam formation. Such a mercury collection method has the advantage of being analyzed by desorption instead of by digestion, thus reducing potential sources of contamination and errors [32] and permitting the recovery of the adsorbing material upon thermal desorption and then its reusability. Therefore, even though noble metal-based adsorbing materials are expensive, their reusability makes these samplers more cost-effective and reduces the costs of measurements [39].

According to the type of material used, the gold-based samplers can collect a particular type of mercury species selectively or can be used for different applications in combination with other membranes. For instance, ion-exchange membranes (like polysulfone) $[40,41]$ are capable of capturing selectively only GOM so that when PASs for TGM are used in combination with these ion-exchange membranes, only GEM can be quantified. Recent advances in nanotechnologies have allowed the production of a variety of highly sensitive nanomaterials with more intriguing properties than the commercial tools [42-44]. Nanostructured materials with unique optical, chemical, magnetic and electronic properties have been designed to improve detection. In particular, the nanostructures employing noble metals have been exploited for their strong surface plasmonic effects, color and current changes. James et al., (2012) [43] reported a sensitive and reusable $\mathrm{Hg}^{0}$ monitoring device based on gold nanoparticles with a limit of detection of approximately $90 \mathrm{ppb}$ in air. McNicholas et al. (2011) [44] reported a very sensitive $\mathrm{Hg}^{0}$ system based in gold nanoparticles deposited on carbon nanotubes with a detection limit of 2 ppb in air. Santos et al. (2017) [34] used a gold NP-impregnated glass disk as a portable device for measuring the worker exposure to highly polluted environments (artisanal gold mining) by exploiting the color change induced by GEM adsorption. Indeed, mercury is also released in the air by several other human activities, such as dentist offices and fluorescence lamp factories, so that daily passive samplers or sensors should be used to monitor the workers' exposure to mercury and prevent the associated health consequences. Therefore, the environmental monitoring and occupational health evaluation would require that sensitive mercury samplers were cheap, rapid and wearable. Gold nanoparticles decorating nanofibers of $\mathrm{TiO}_{2}$ have been designed to adsorb and reveal mercury from the air up to between 6 and 2 ppt $_{\mathrm{vol}}$ [45]. Salcedo et al. (2018) developed a device based on a cuprous iodide/polystyrene composite for mercury, exhibiting reddish color in the presence of $\mathrm{Hg}^{0}$ [46]. This device was able to work from 61 to $270 \mu \mathrm{g} / \mathrm{m}^{3}$ (high polluted), and the detection was performed by an image processing program utilizing a smartphone picture of the sampler.

Previously, Macagnano et al., (2018), designed a simple-to-prepare and -use, low-cost and re-deployable passive axial air sampler (PAS) based on a film of titania NPs (about $100 \mu \mathrm{m}$ thick) finely decorated with gold NPs ( $\left.\mathrm{Au} @ \mathrm{TiO}_{2} \mathrm{NPs}\right)$ [35]. The PAS was also supported by a fibrous quartz filter disk suitable for thermal desorption. This type of PAS was tested in controlled lab conditions at different parameters (temperature, relative humidity and mercury concentration) in order to assess the performance of the adsorbing material. The $\mathrm{Au} @ \mathrm{TiO}_{2} \mathrm{NP}$ film showed an absorption efficiency of $\approx 95 \%$, no high augmentation of uncertainty due to temperature and relative humidity, and reusability in a controlled environment. Therefore, the nanostructured and heterogeneous film was confirmed to be quite efficient in capturing and storing mercury vapor. However, such a thick layer, due to disc handling for the following thermal desorption, likely underwent microfractures, thus changing its surface-related properties. In the present study, we investigated the effects of layer thickness and arrangement on the mercury diffusion and sampling rate values when the PASs were exposed to a low 
polluted site and for different time. Therefore, samplers containing mercury adsorbing layers and with $\mathrm{Au} @ \mathrm{TiO}_{2}$ NPs were fabricated and housed in customized holders and then underwent a series of thermal cycles for mercury desorption. PASs efficiency after each thermal treatment was also assessed.

\section{Materials and Method}

All chemicals were purchased from Sigma-Aldrich (Merck KGaA, Milan Italy) and used without further purification: polyvinylpyrrolidone (PVP, 1,300,000 g/mol), titanium (IV) oxide particles $\left(\mathrm{TiO}_{2}\right.$ anatase, $\leq 25 \mathrm{~nm}$ diameter, CAS 1317-70-0) and gold (III) chloride hydrate ( $\left.\mathrm{HAuCl}_{4}, 99.999 \%\right)$. Ultrapure water $\left(5.5 \times 10^{-8} \mathrm{~S} / \mathrm{cm}\right)$ was produced by MilliQ-EMD Millipore. Fibrous quartz filters (Whatman ${ }^{\mathrm{TM}}$, Little Chalfont, UK) $400 \mu \mathrm{m}$ thick with $\approx 2 \mu \mathrm{m}$ pore diameter dimension and $\leq 3 \mu \mathrm{m}$ fiber width were used as scaffolding and cut in $20 \mathrm{~mm}$ diameter disks.

\subsection{Preparation of $\mathrm{Au} @ \mathrm{TiO}_{2} \mathrm{NP}$ Dispersion}

The $\mathrm{TiO} 2$ particle gold decoration procedure was previously described by authors [35]. Briefly, a water dispersion of $\mathrm{TiO}_{2}$ particles $(3.71 \mathrm{mg} / \mathrm{mL})$ containing $11.0 \mathrm{mg} / \mathrm{mL}$ of PVP (capping agent) and $1.10 \mathrm{mg} / \mathrm{mL}$ of $\mathrm{HAuCl}_{4}$ was exposed to UV light for $1 \mathrm{~h}$ (GR.E. $500 \mathrm{~W}$ Helios Italquartz lamp). After exposure, the color turned from light yellow to dark purple. $\mathrm{TiO}_{2} \mathrm{NPs}$ were used to exploit their photocatalytic activity to reduce $\mathrm{HAuCl}_{4}$ and obtain gold nanoparticles anchored to $\mathrm{TiO}_{2}\left(\mathrm{Au} @ \mathrm{TiO}_{2}\right)$ without any additional linkage.

$\mathrm{Au} @ \mathrm{TiO}_{2}$ NP dispersion was centrifuged at $9000 \mathrm{rpm}$ for 20 min (REMI Neya-16R centrifuge); the particles sediment was sonicated in water and then centrifuged again. This procedure was replicated three times to remove most of the PVP and to achieve an $\mathrm{Au} @ \mathrm{TiO}_{2} \mathrm{NP}$ water dispersion (13.3 $\mathrm{mg} / \mathrm{mL})$.

\subsection{PAS Fabrication}

The principles of the PASs here fabricated were the followings: The PASs worked exploiting the unassisted axial diffusion route of the gaseous mercury through a diffusive membrane, along a glass vessel (diffusion path), until reaching the adsorbing membrane. Hence, the PAS was composed of a see-through borosilicate vessel, a cap made of a nylon membrane for gas diffusion and particulate stopping, a locking ring to keep the adsorbing membrane to the vessel bottom, and finally the adsorbing membrane onto the quartz fibrous substrate (Figure 1C,D).

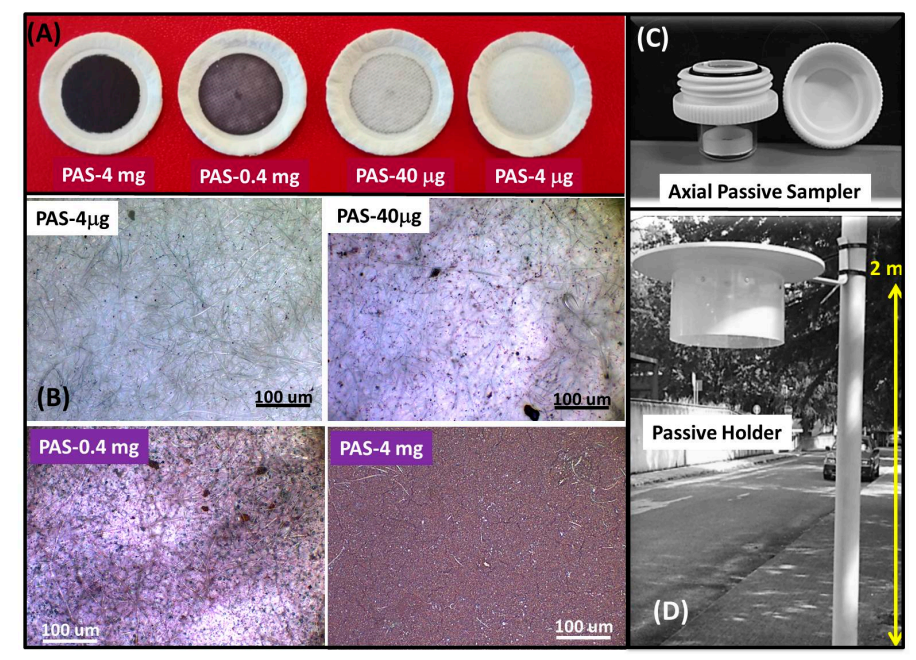

Figure 1. Composite picture (right) showing the quartz microfibrous filters upon $\mathrm{Au} @ \mathrm{TiO}_{2}$ nanoparticle (NP) deposition (A). The different colors of the discs is related to the amount of Au@TiO $2 \mathrm{NPs}$ 
mass-loaded. Images are captured by camera (A) and optical microscopy (B). (C) A passive sampler architecture showing the double screw cap and the glass vessel with the polytetrafluoroethylene (PTFE) ring inside. (D) The global monitoring system with the customized shelter housing up to eight passive air samplers (PASs), and anchored to a pole at about $2 \mathrm{~m}$ height from the ground (breathing zone).

\subsubsection{Adsorbing Membrane}

The adsorbing systems were based on commercial fibrous quartz filters decorated with $\mathrm{Au} @ \mathrm{TiO}_{2}$ NPs by drop-casting as follows: An aliquot of $300 \mu \mathrm{L}$ of the $\mathrm{Au} @ \mathrm{TiO}_{2} \mathrm{NP}$ water dispersion was poured all at once onto a $20 \mathrm{~mm}$ diameter fibrous quartz filter disk, using a suitable mask with $12.5 \mathrm{~mm}$ diameter aimed at concentrating the suspension on the filter. The mask was manually pressed onto the filter disk. This procedure provided a reproducible size of the exposure surface area and a homogenous deposition of the mass of interest over the filter. The reproducibility of the deposition method was assessed in about 120 adsorbing layers, where the deposition of the water dispersions resulted in $4.3 \pm 0.3 \mathrm{mg}$ of $\mathrm{Au} @ \mathrm{TiO}_{2} \mathrm{NPs}$. Some absorbent paper was placed underneath to collect the aqueous solution leaching from the quartz filter.

Similar volume solutions but with different $\mathrm{Au} @ \mathrm{TiO}_{2} \mathrm{NP}$ concentrations were used in the procedure to obtain distinct masses of $\mathrm{Au} @ \mathrm{TiO}_{2} \mathrm{NPs}$ deposited onto the quartz filters. By the way, the weight of the filter was measured before and after deposition of $300 \mu \mathrm{L}$ of $\mathrm{Au} @ \mathrm{TiO}_{2} \mathrm{NP}$ water dispersions to calculate the mass deposited. Specifically, different dispersions generated 4, 0.4, 0.04 and $0.004 \mathrm{mg}$ of the composite layers, named as PAS4mg, PAS0.4mg, PAS40 $\mu$ g and PAS4 $\mu \mathrm{g}$, respectively.

The $\mathrm{Au} @ \mathrm{TiO}_{2} \mathrm{NP}$-decorated quartz scaffolds were then oven dried at $105^{\circ} \mathrm{C}$ for about $24 \mathrm{~h}$ to remove totally the water molecules adsorbed on the filters and finally heated at $550^{\circ} \mathrm{C}$ for $15 \mathrm{~min}$ under clean air flux to remove any trace of $\mathrm{Hg}$ possibly adsorbed onto the gold particles during the deposition procedure and contaminating the resulting adsorbing membranes.

\subsubsection{PAS Assemblage}

All the components of PAS containers were dipped in an aqueous solution of $\mathrm{HCl}(0.01 \mathrm{~N})$ to remove most of the adsorbed mercury and then rinsed with ultrapure water $(0.055 \mu \mathrm{S} / \mathrm{cm})$ in a ultrasonic bath (Branson Ultrasonic 1800, $30 \mathrm{~min}, 50^{\circ} \mathrm{C}$ ) and finally under ultrapure water flow. Then, they were left to dry in a glove-box under a flow of dry and pure air coming from a cylinder (5.0, Praxair) and passing through a home-made activated carbon cartridge. The assembling of the PASs occurred inside the glove-box to avoid any further contamination. The adsorbing membranes were then placed into the see-through borosilicate vessels $(2.7 \mathrm{~cm} \times 2.4 \mathrm{~cm}$, height $\times$ diameter $)$ and blocked to the base by polytetrafluoroethylene (PTFE) rings. The containers were then plugged with customized double screw caps (Figure 1C) (Spaziani Rolando S.r.l.), where the top cap $(4.1 \mathrm{~cm} \times 1.4 \mathrm{~cm})$ closed and sealed the PAS to prevent $\mathrm{Hg}$ diffusion into the vessel during PAS storage and transport. The bottom cap $(4.1 \mathrm{~cm} \times$ $1.7 \mathrm{~cm})$, instead, was sealed on the top with the diffusive nylon membrane $\left(10 \times 10^{3} \mu \mathrm{m}^{2}\right.$ each pore area), enabling both gas diffusion and dust particle stopping during PAS exposure to the atmosphere for mercury monitoring.

\subsubsection{Monitoring System Arrangement}

To generate operative monitoring systems, customized shelters were fabricated to host the PASs and protect them from environmental (sunlight, heating, dust and rain) disturbances and interferences. Each shelter consisted of a top opaque rigid plastic plate $(\mathrm{r}=15 \mathrm{~cm})$ covering a $\approx 10 \mathrm{~cm}$ high central cylinder $(\mathrm{r}=9.5 \mathrm{~cm})$ of PP (polypropylene) to shield the PASs hosted internally and prevent possible sidewise weather interferences during $\mathrm{Hg}$ sampling. The plastic shelters were fabricated to host up to eight PASs, each arranged in a circle and held by clamps (Figure 1D).

Before starting the measurements, the various PASs loaded with distinct $\mathrm{Au} @ \mathrm{TiO}_{2} \mathrm{NP}$ masses, then with a different surface density, were housed in the shelters. Briefly, the top cap of the assembled PASs were removed, and the opened PASs were fixed upside down in the shelter, i.e., with the diffusive 
membrane, exposed to the atmosphere, following a randomly distribution according to a 5:3 ratio between $\mathrm{Au} @ \mathrm{TiO}_{2} \mathrm{NP}$-loaded filters and controls (blanks, i.e., sealed PASs). PASs with different $\mathrm{Au} @ \mathrm{TiO}_{2} \mathrm{NP}$ surface density were mounted in each shelter. Five replicates per each surface density of $\mathrm{Au} @ \mathrm{TiO}_{2}$ NPs deposited $(\mathrm{n}=20)$ and 12 control samples $(\mathrm{n}=12)$ were tested according to the experimental plan. Each PAS-loaded shelter was then mounted on a pole $2 \mathrm{~m}$ high (breathing zone). At the same time, a number of PAS4mg $(\mathrm{n}=96)$ were housed in 12 shelters and mounted onto 4 different poles (in groups of 3) (Figures S5 and S6), 36 of which used as Blanks and tested over 1 year.

\subsection{Measurements and Analysis}

A double experimental approach was carried out: the first one to investigate the relationship between the layer density and the passive features; the second one to test the passive features over the time.

\subsubsection{Measurements}

All the passive samplers were used for different periods from 1 to 200 days within 1 year to test the features of the PASs with diverse adsorbing capacities when exposed to the air for various durations (daily, weekly, monthly until half-yearly). At the end of each monitoring period, the PASs were immediately plugged and sealed with the top cap and transferred to the laboratory. The monitoring site was the campus of the CNR Research Area (Rome) (42.11, 12.64 and $45 \mathrm{~m}$ for latitude, longitude and elevation coordinates, respectively).

\subsubsection{Resampling}

PASs were also assessed for their effectiveness in $\mathrm{Hg}$ resampling in trials consisting in 35 cycles of sorption-desorption. Briefly, a separate set of three PASs loading the same mass of $\mathrm{Au} @ \mathrm{TiO}_{2} \mathrm{NPs}$ (PAS-4mg, specifically) underwent 35 cycles of outdoor exposure for periods ranging between 1-8 days followed by thermal desorption. Their results were compared to the Tekran ${ }^{\circledR}$ estimated values.

\subsubsection{Analyses}

At the time of $\mathrm{Hg}$ measurements, the mercury adsorbed onto the membranes was measured by thermal desorption and Atomic Spectroscopy according to the EPA Method 7473 (SW-846) [47] as follows. Each double screw cap was unplugged; the PTFE ring was removed; and the $\mathrm{Au} @ \mathrm{TiO}_{2}$ NP-loaded filter disc was withdrawn from the vessel, placed in a hermetic quartz crucible and heated in the oven (Forni De Marco, Rome, Italy) at $\approx 550^{\circ} \mathrm{C}$. During heating, pure air was used as a carrier to collect and inject the $\mathrm{Hg}^{0}$ vapors generated in the quartz crucible to the mercury analyzer (Tekran ${ }^{\circledR}$ 2537A, CVAFS, Toronto, Canada) in order to measure the amount of adsorbed gaseous mercury. Each desorbed and restored quartz membrane was placed inside another clean and dry PAS where it was stored; then, it was ready to be reused for further measurements.

Environmental parameters, like temperature and relative humidity, were provided by a HMP7-Vaisala probe placed outdoors and close to the measurement area, while mercury concentration (TGM) was measured by Tekran ${ }^{\circledR}$ 2537A. Data were collected and analyzed by Origin ${ }^{\circledR} 2018$ (Ver. 95E).

Based on the $\mathrm{Hg}$ values obtained through the measurements carried out, the rate of adsorption during the exposure time was calculated as the amount of $\mathrm{Hg}$ adsorbed per unit of time and expressed as ng/day.

The sampling rate, indeed, was calculated based on the assumption that the slope of the linear regression model can be related to the empirical value of the sampling rate according to the Equation (1) [48]:

$$
S R_{\text {LinReg }}=m_{H g} /(C \cdot t)
$$

where $S R_{\text {LinReg }}$ is the slope of the linear regression, $m_{H g}$ is the adsorbed mass of mercury, $C$ the measured concentration and $t$ the number of the exposure days. The sampling rate in passive analysis is 
a crucial parameter related to the amount of analyte collected by the sampler per unit time at constant concentration. SR quantifies the volume of air pollutant effectively stripped per unit of time. Theoretically, it depends on both the diffusion coefficient (Fick's First Law) of the adsorbing compound and the geometrical parameters (2) [49]:

$$
S R=D A / L
$$

where $D$ is the coefficient of molecular diffusion (pressure and temperature dependent), $A$ is the surface area collecting the analyte, and $L$ is the diffusive path length.

\subsection{Material Characterization}

The nanostructured layers were characterized by Atomic Force Microscopy (AFM, Flex-AFM, Liestal, Switzerland), which captured images of the layer surface in tapping mode using 190Al-G tips, $190 \mathrm{kHz}, 48 \mathrm{~N} / \mathrm{m}$. The roughness of the PAS4mg layer was measured using SPIP 6.7.6 software (Image Metrology, Hørsholm, Denmark) over image areas of $100 \mu \mathrm{m}^{2}(10 \times 10 \mu \mathrm{m})$. A plane correction process was performed on all of the topographical images. The roughness parameter here reported within the defined area was the roughness average (i.e., the difference in the height of each point compared to the arithmetical mean of the surface) (Sa) measured both over the whole surfaces and each micrograin (up to 50), respectively. SEM (Scanning Electron Microscope Jeol JSM 6010LA) micrographs were also taken with and without a gold sputter coating in a Balzers MED010 unit. High-Resolution Transmission Electron Microscopy (HR-TEM) analysis of the $\mathrm{Au} @ \mathrm{TiO}_{2} \mathrm{NP}_{\text {powder was performed }}$ by a ZEISS Libra 200FE microscope (Oberkochen, Germany). The size distributions were manually calculated, counting more than 400 NPs by iTEM software (Olympus SIS, Muenster, Germany).

Optical micrographs were captured by DMC4500 (5 MPx) camera mounted on the optical microscope (Leica DM2700M) for the quality evaluation of the nanocomposite filter layer coverage.

\section{Results and Discussion}

The doping of titania $\left(\mathrm{TiO}_{2}\right)$ with nano-gold decorations has recently enabled the development of highly efficient materials for sensors, energy, smart coating and environment [50-54]. In the present study, the authors selected one of the simplest, cost-effective and green procedures [35]: AuNP-decorating $\mathrm{TiO} 2$ were synthesized by reducing $\mathrm{HAuCl}_{4}$ onto titania particles in aqueous suspension by a UV-light-catalyzed reaction. Hence, no sophisticated technologies or harsh solvents were used. This process caused a significant increase in the adsorbing surface exposed to atmospheric mercury. Among the thermally resistant substrates, fibrous quartz was selected to keep porous the film deposited by drop-casting and preventing its excessive packing, thus both facilitating the mercury adsorption and the following thermal desorption during the passive membrane regeneration.

\subsection{PAS Characterization}

Depending on the amount of $\mathrm{Au} @ \mathrm{TiO}_{2}$ NPs deposited, the filters appeared differently colored. Of course, it depended on the distribution of the nanoparticles onto the substrate. The surface density changed from $3.26 \times 10^{-2} \mathrm{mg} / \mathrm{mm}^{2}$ to $3.26 \times 10^{-5} \mathrm{mg} / \mathrm{mm}^{2}$ when the loaded mass passed from $4 \mathrm{mg}$ to $4 \mu \mathrm{g}$. Figure 1 presents a photograph of the four quartz filters coated with the different $\mathrm{Au} @ \mathrm{TiO}_{2}$ NP loadings (Figure 1A) and their optical microscope pictures (Figure 1B). Both groups of images show that at the lowest concentration (PAS4 $\mu \mathrm{g}$ ), the substrate looks white (that is the pristine color of the filter). In the optical microscope pictures, the original white fibers showed some purple aggregates $\left(\mathrm{Au} @ \mathrm{TiO}_{2} \mathrm{NPs}\right)$ appearing as tiny spots in the matrix that increased in number by increasing the mass of $\mathrm{Au} @ \mathrm{TiO}_{2}$ NPs deposited, causing the intensity of the purple color to also increase.

Optical microscope pictures highlighted that the complete coverage of the fibrous matrix was achieved when a $4 \mathrm{mg} \mathrm{Au@} \mathrm{TiO}_{2} \mathrm{NP}$ mass was loaded (Figure 1B), i.e., when the surface density was at least $3.26 \times 10^{-2} \mathrm{mg} / \mathrm{mm}^{2}$. The complete coverage was confirmed by SEM analysis. The top view 
of the surface of the fibrous quartz, captured by SEM upon drop deposition of 4 mg Au@TiO $-\mathrm{NPs}_{2}$ and thermal treatments (PAS-4mg), showed that the filter was coated by the nanocomposite film (Figure 2A), whereas the $\mathrm{Au} @ \mathrm{TiO}_{2}$ NPs generated aggregates that induced an extremely rough and wrinkled film surface. The plot of the normal distribution (Gauss curve) of the aggregate size indicated that the mean diameter was $1.49 \pm 0.88 \mu \mathrm{m}$ (Figure $2 \mathrm{~B}$ inset).

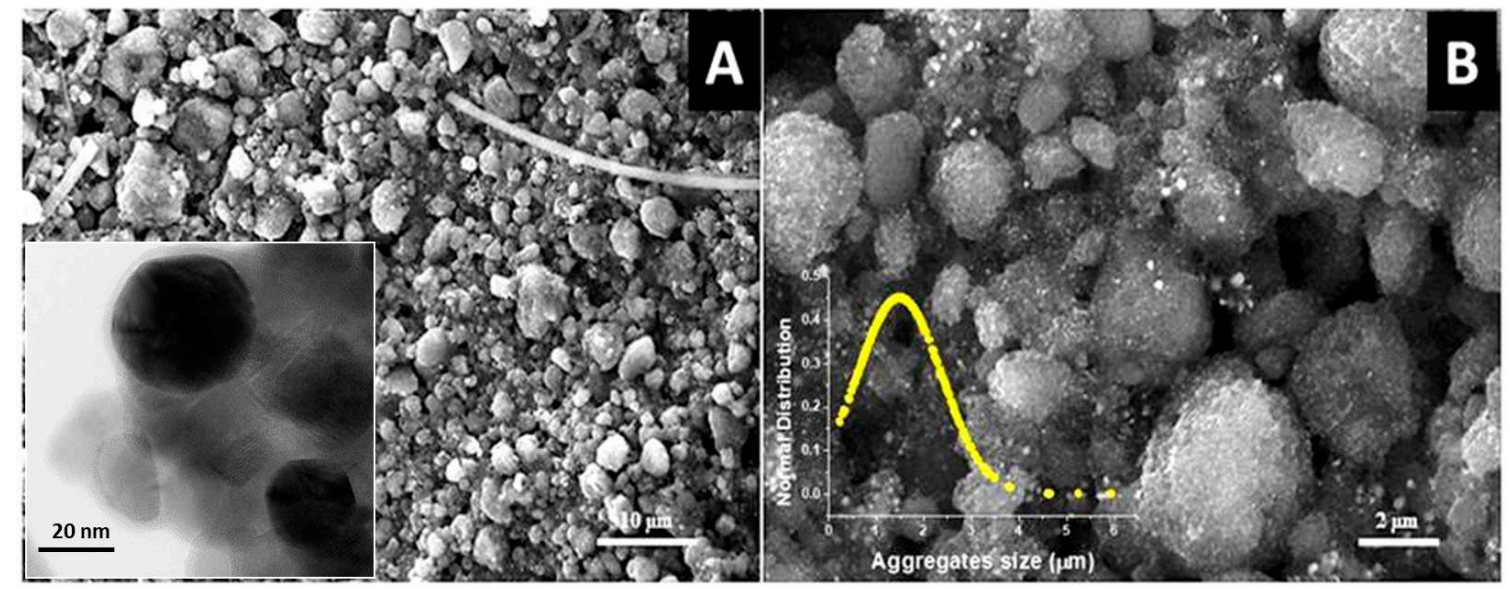

Figure 2. SEM micrographs of PAS4mg at $1700 \times(\mathbf{A})$ and $7000 \times(\mathbf{B})$ magnification showing an almost complete coverage of the quartz fibers with $\mathrm{Au} @ \mathrm{TiO}_{2} \mathrm{NPs}$ and micrometric aggregates on the top. Inset (A) shows a HR-TEM micrograph of the powder; inset (B) depicts the normal distribution of the diameter size of the microaggregates.

A higher magnification of the surface pointed out the presence at the film surface of pillars, valleys, canyons as well as some tiny voids between the $\mathrm{Au} @ \mathrm{TiO}_{2} \mathrm{NP}$ aggregates facilitating the gas diffusion through the PAS (Figure 2B). In addition, the nanoparticle grains showed a rough surface maybe caused by the peculiar architecture of the composite nanoparticles. The nanocomposite material was previously characterized by authors [35].

Figure S1A-C and the inset picture in Figure 2A (an HR-TEM micrograph) confirmed the presence of highly crystalline and globous-shaped gold nanoparticles (a mean of about $32.6 \mathrm{~nm}$ ) in close contact with the anatase crystalline support (AuNPs appear slightly darker with respect to the anatase support).

Then, the nature and the final architecture of the nanocomposite layer looked responsible of the high roughness of the material and then of the high contact surface. AFM analysis (2D- and 3D-map) of a $10 \times 10 \mu \mathrm{m}$ surface topography of the PAS4mg surface confirmed the presence of a nanoroughness due to the arrangement of the microaggregates in the deposited film distributed throughout the surface $(\mathrm{Ra} \approx 107 \pm 25 \mathrm{~nm}$ ) (Figure 3A,B, respectively).

The similar analysis performed on a smaller area focused on single microaggregates proved the presence of a nanoroughness even on each micrograin ( $\mathrm{Ra} \approx 11 \pm 6 \mathrm{~nm}$, average roughness) previously observed also in the SEM picture of Figure 2B, whereas each micrograin appeared exceptionally wrinkled. However, in the AFM micrographs, the $\mathrm{Au} @ \mathrm{TiO}_{2} \mathrm{NP}$ grains also appeared densely packed, although providing some spaces between the particles (darker areas).

A comparable result had already been observed by the authors on the surface of a thicker layer (10 mg mass) of the same material dropped on the same substrate [35], confirming that such a microgranular surface arrangement was not dependent on the thickness but on the preparation procedures and the material properties. 

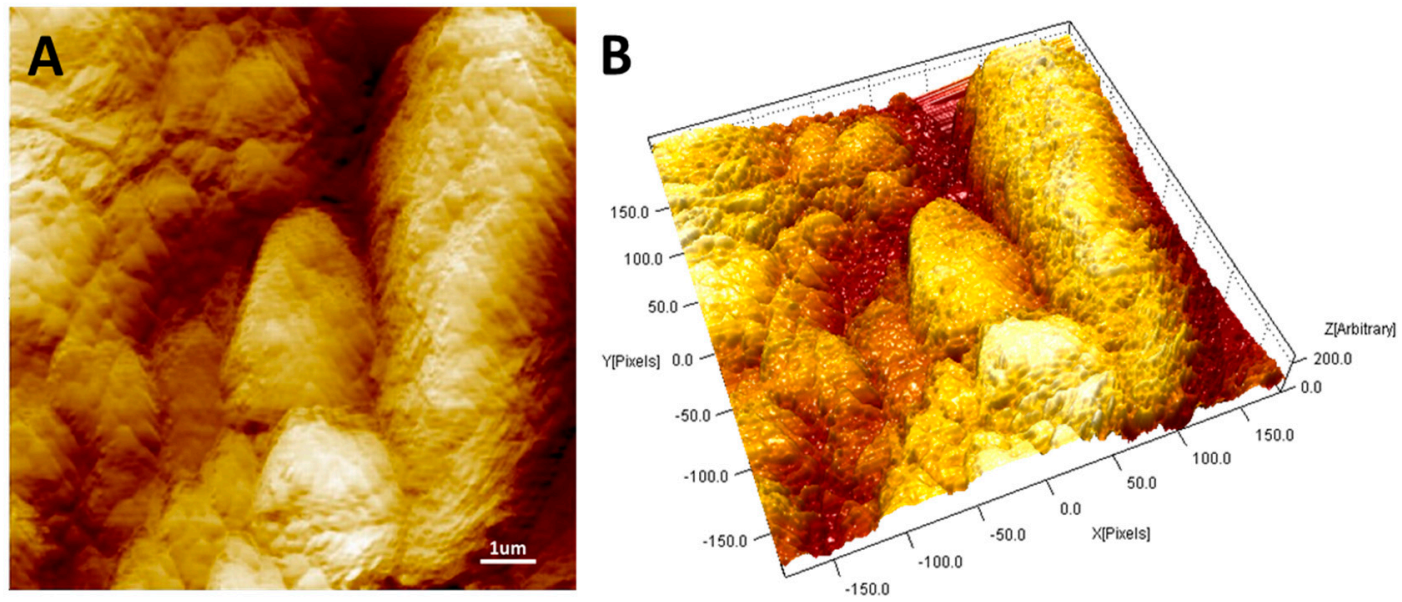

Figure 3. (A) Two-dimensional and (B) three-dimensional PAS4mg Atomic Force Microscopy (AFM) micrographs $(10 \times 10 \mu \mathrm{m}$ surface area).

Looking at the cross-section of a PAS-4mg substrate, the one most loaded (Figure 4A), that is, the aggregates of $\mathrm{Au} @ \mathrm{TiO}_{2} \mathrm{NPs}$ in the deposition zone, appeared distributed within $50 \mu \mathrm{m}$ depth, with the nanocomposite clusters being more concentrated approaching the surface until forming a densely packed layer on top (Figure 4B).
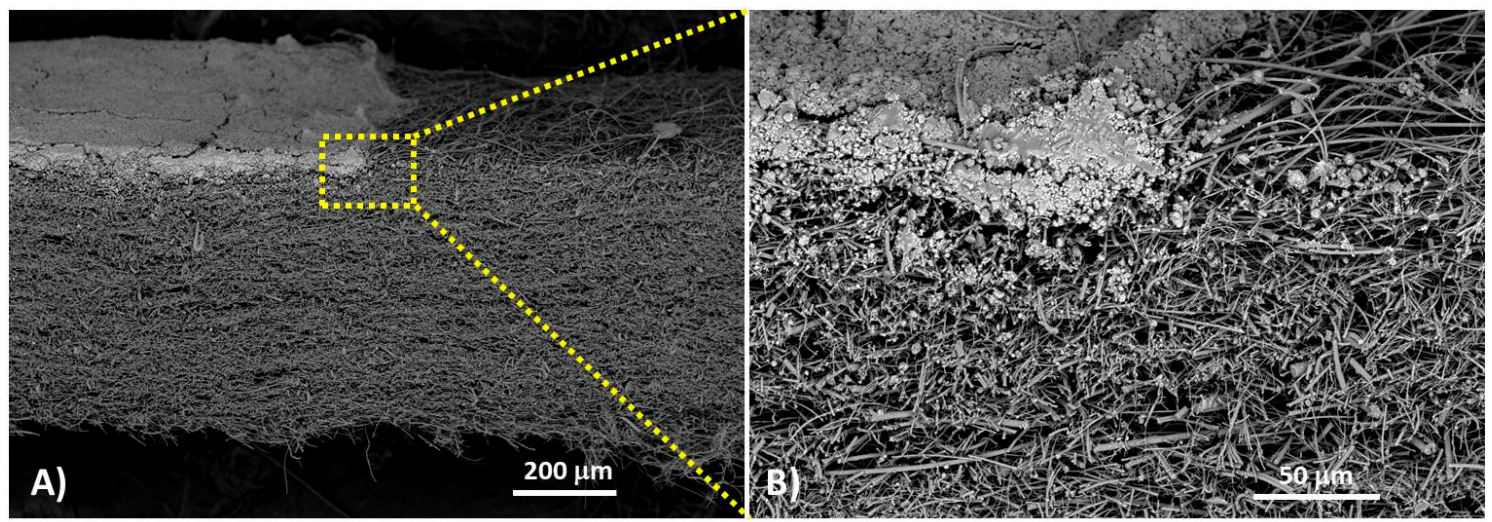

Figure 4. SEM micrographs (backscattered electron composition image-BEI, $10 \mathrm{kV}$, no gold sputtered, $90 \times$ ) of a cross-section of a PAS4mg along the edge of the $\mathrm{Au} @ \mathrm{TiO}_{2}$ layer showing the layer arrangement on top of the quartz filter (A); a magnification of the particle distribution under the top layer $(430 \times)(\mathbf{B})$.

However, the interface between the top layer and the fibrous substrate underneath was not defined by a definite boundary. On the contrary, the aggregates and the fibers appeared as integrated into a composite fibrous scaffold, where smaller $\mathrm{Au} @ \mathrm{TiO}_{2} \mathrm{NP}$ clusters were bound to the fibers at greater depth, and larger microaggregates were observed close to the surface until forming the dense layer aforementioned (Figure 4B). Because of the peculiar architecture of the ${\mathrm{Au} @ \mathrm{TiO}_{2}} \mathrm{NP}$ film, the PAS-4mg filter was expected to display a highly interactive surface and fast adsorption processes (as well as thermal desorption) but was also permeable enough, enabling gas diffusion.

Moreover, since the top layer was partially underpinned by the quartz microfibers, it was strong enough to be handled without undergoing damages or fractures. On the other hands, the fibrous quartz substrates coated with smaller amounts of nanoparticles involved the formation of fragmented and uneven films characterized by islands made of differently sized aggregates and adsorbed onto the fibers (Figures S2-S4).

Here, due to substrate handling, an easier detachment of the nanoparticles from fibers since they were only physically joined was expected. Therefore, PAS4mg $\left(\mathrm{dS} \approx 32.6 \mu \mathrm{g} / \mathrm{mm}^{2}\right)$ looked decorated 
with the minimum amount of material capable of ensuring the development of a thin film onto the substrate used.

\subsection{PAS Exposure}

The various PASs loaded with distinct $\mathrm{Au} @ \mathrm{TiO}_{2}$ NP masses were then measured in the amount of mercury adsorbed upon exposure for different periods to evaluate the rate of adsorption of the gaseous mercury and the corresponding sampling rate (SR), as well as to assess the dependence of the amount of $\mathrm{Hg}$ adsorbed on the mass of $\mathrm{Au} @ \mathrm{TiO}_{2}$ NPs loaded in the PASs and the effectiveness of the adsorbing membranes (MSs).

During the exposure time of the PASs, the gaseous Hg concentration was measured by Tekran ${ }^{\circledR}$, which is one of the most widely adopted instrument for continuous measurements of atmospheric TGM $\left(\mathrm{ng} \cdot \mathrm{m}^{-3}\right)$. In the present work, Tekran ${ }^{\circledR}$ was used with the dual function of environmental monitoring system and PAS-Hg analyzer. The average daily $\mathrm{Hg}$ concentration in the atmosphere through the investigated period measured by Tekran ${ }^{\circledR}$ was $1.24 \pm 0.32 \mathrm{ng} / \mathrm{m}^{3}$, with daily and seasonal fluctuations. The analysis of mercury adsorbed on PAS as a function of the exposure time (the uptake curves of Figure 5) for all the types of PASs showed that PASs loaded with different mass of $\mathrm{Au} @ \mathrm{TiO}_{2}$, as well as area density, collected approximately and linearly the same amount of $\mathrm{Hg}$ until 8 days of exposure (Figure 5A). However, the different effects of the architecture of the layers were underlined initially in PAS40 $\mu$ g and PAS4 $\mu$ g, which appeared saturated after 7-8 days of exposure, when the gaseous mercury adsorbed per day started to decrease. Furthermore, prolonged exposure of these PASs up to 40 days caused a decrease in the total absorbed mass of mercury. Such an effect could be also due to the detachment of the adsorbing particles from the filter following the disc handling for the thermal desorption procedures. Conversely, PAS0.4mg samples, having a higher NP loading and surface density $\left(3.26 \mu \mathrm{g} / \mathrm{mm}^{2}\right)$, followed a linear trend until $\approx 23$ days of exposure. After that, they deviated from linearity, causing the adsorbing rate to start decreasing. The gray line in Figure 5A represents the linear regression of PAS4mg values forced passing through the origin. The linear shape confirms that this amount of $\mathrm{Au} @ \mathrm{TiO}_{2}$ NPs loaded on PAS (4 mg) with the highest area density $\left(32.6 \mu \mathrm{g} / \mathrm{mm}^{2}\right)$ as the threshold value, in our study, is capable of providing a constant rate of mercury adsorption until about 60 days of exposure. Here, the calculation of the rate of adsorption within the first sixty days reported a value of about $18.5 \pm 0.44 \mathrm{pg} / \mathrm{day}$ at a $\mathrm{Hg}^{0}$ average concentration in air of about $1.24 \pm 0.32 \mathrm{ng} / \mathrm{m}^{3}$, which is a common concentration in low-polluted sites [28]. Therefore, $\approx 1.5 \%$ of the average gaseous concentration of mercury could be adsorbed daily. Such a linear behavior in mercury uptake suggests that the adsorbent layer had not approached its total adsorption capacity (saturation) for at least 60 days of exposure. However, a slight decrease in the adsorption rate occurred when these PASs was exposed for a longer period. Figure 5B depicts in more detail a non-linear fitting of the curve with an apparent saturation of the binding sites over the second half of the sampling time (more than 100 days). However, this result could depend on several reasons not entirely related to the binding sites saturation. For instance, it could be due to the seasonal variability of the mercury concentration, which decreased from summer to autumn $\left(1.34 \pm 0.44 \mathrm{ng} / \mathrm{m}^{3}\right.$ and $1.18 \pm$ $0.44 \mathrm{ng} / \mathrm{m}^{3}$, respectively) (confirmed later by Figure 8). On the other hand, the possible interference of other compounds in the polluted atmosphere interacting with the adsorbing surface of PASs during the prolonged exposure could also reduce the adsorption efficiency of the devices, thus preventing $\mathrm{Hg}$ from reaching the Au-NPs. Even chemical reactions occurring at the interface between air and the Au@ $\mathrm{TiO}_{2}$ NP aggregate surfaces and resulting in the loss of $\mathrm{Hg}$ could not be excluded. For instance, ozone could remove the adsorbed $\mathrm{Hg}$ affecting the final result $[32,55,56]$. In any case, these results proved that the PAS4mg membrane was properly working within a hundred days. Taking into account the daily $\mathrm{TGM}_{\mathrm{av}}$ concentration values measured by Tekran ${ }^{\circledR}$, the daily sampling rates were calculated, from Equation (1), per each PAS (Figure 6). 

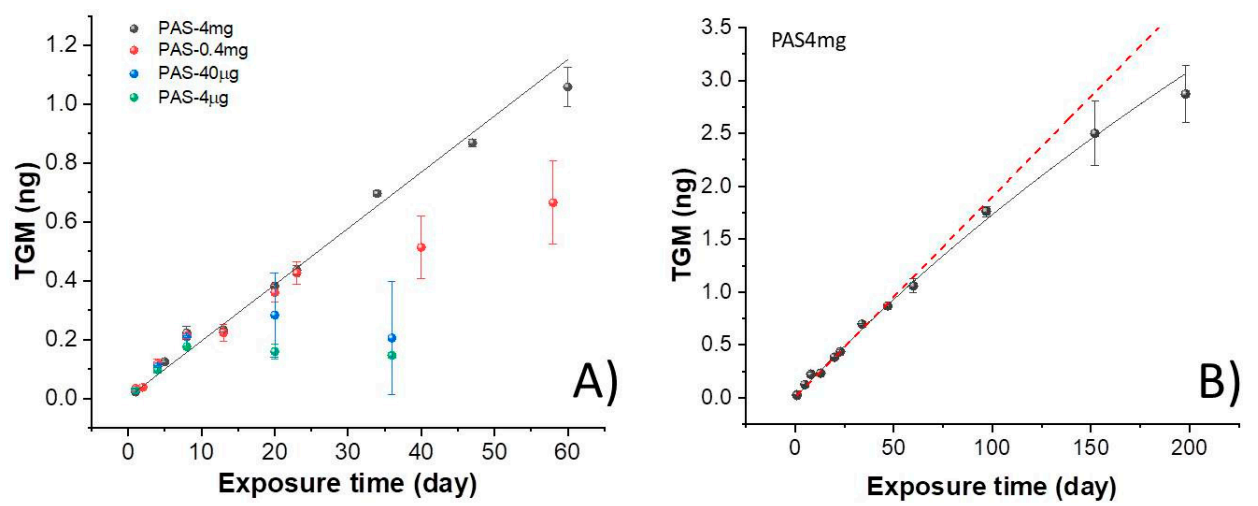

Figure 5. (A) Uptake curves (adsorbed mercury versus exposure time) of PAS4mg, PAS-0.4mg, PAS40 $\mu \mathrm{g}$ and PAS4 $\mu \mathrm{g}$ samples. Vertical bars correspond to standard deviation and dark gray line to linear fit of the PAS-4mg values $\left(R^{2}=0.995\right)$. (B) A non-linear fitting of PAS4mg curve within an exposure time of 198 days compared to a linear fitting (the red dotted line).

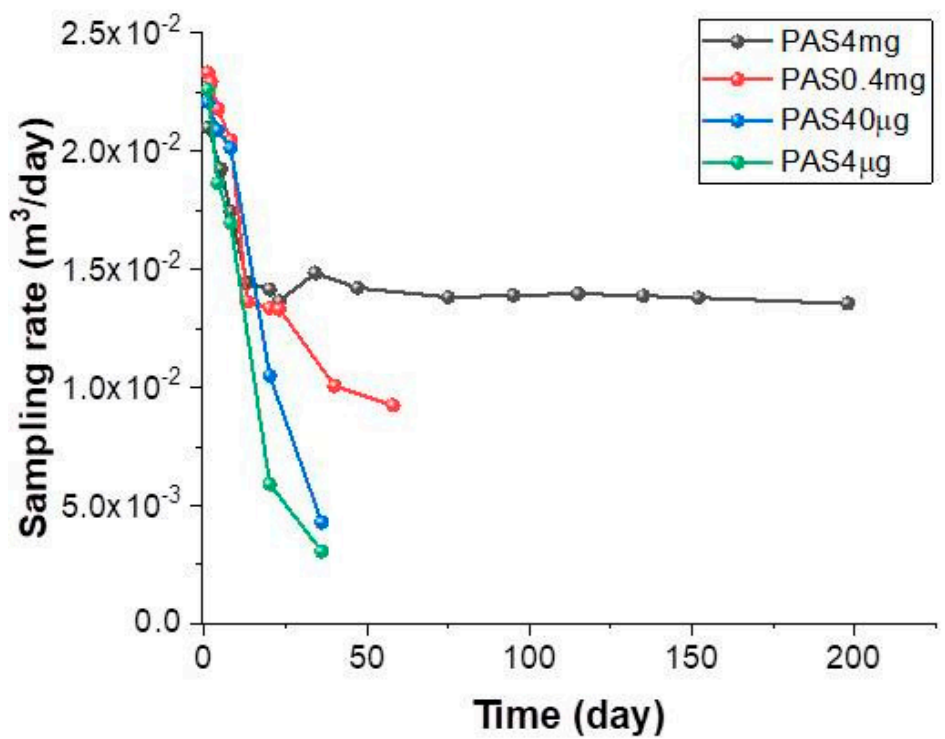

Figure 6. PAS sampling rate calculated for the samplers coated with different $\mathrm{Au} @ \mathrm{TiO}_{2}$ masses and exposed to outdoor air for increasing periods (days).

It is known that $\mathrm{SR}$ is strongly dependent on the characteristics of the pollutant and the design of the sampler [57].

In the figure, high SR values (in the range between $2.0-2.3 \times 10^{-2} \mathrm{~m}^{3} / \mathrm{d}$ for all the $\mathrm{Au} @ \mathrm{TiO}_{2}$ NP-loaded PASs) during the first days of exposure are depicted, followed by a sharp decrease over the first week, but with different slopes in the various PASs.

Such a decreasing trend of SR was also observed by Papa et al. (2018) in axially diffusive PASs based on gold NPs deposited onto quartz fibers and differently arranged on the surface. The SR value was confirmed to be higher the first day of exposure, then decreasing gradually during the first week until stabilizing during the following days [36]. In the present study, too, after the first week of exposure, SR remained constant (about $1.398 \times 10^{-2} \pm 0.051 \times 10^{-2} \mathrm{~m}^{3} /$ day) for both PAS- $0.4 \mathrm{mg}$ and PAS-4mg until $\approx 30 \mathrm{~d}$. In PAS4mg, SR remained apparently almost stable even for a longer period, with a maximum decrease of about $3 \%\left(1.356 \times 10^{-2} \pm 0.061 \times 10^{-2} \mathrm{~m}^{3} /\right.$ day) after 198 days (Figure 6). Conversely, the 4-40 $\mu \mathrm{g}$ masses reported a constant decline in SR without ever reaching a constant value. Presumably, higher SR values might occur when the gaseous elemental mercury is adsorbed onto the outside sites of the external layer of $\mathrm{Au} @ \mathrm{TiO}_{2} \mathrm{NPs}$. Once all external sites are occupied by 
mercury, $\mathrm{Hg}$ in air should diffuse through the channels within the layer reaching the inner sorption sites [58], thus increasing the diffusive path L (Equation (2))and reducing the SR value.

The concentration of the gaseous mercury upon the adsorbent material is, indeed, low at the beginning of sampling, resulting in a higher concentration gradient with a faster adsorption of the gaseous mercury. Since uptake is a cumulative process and SR is relative to the whole sampling period, the initial values can be considered irrelevant when PAS works for more than 1 week. Since the mercury stripping seems constant until 200 days, the efficiency of the PASs seems to be affected only slightly by the parameters described above and lowering Au features. Therefore, the non-linearity of the curve in Figure 5B should be largely due to the lowering of the TGM and then of the related uptake (afterwards confirmed by Figure 8). On the other hand, the dramatic SR daily drop for the less loaded PASs (Figure 6) means that, despite their sensitivity to mercury, they cannot be used for long deployments. The higher sampling rates of both PAS0.4mg and PAS40 $\mu \mathrm{g}$ within the first week when compared to the PAS4mg one confirm their relationships with the surface area across which diffusion occurs, which is expected to be higher in less compact architectures. Therefore, concerning the chance of using the investigated passive samplers, the data suggest that there is a mass threshold of the described adsorbing layer and then a surface density, which necessary to make available these devices for monitoring campaigns.

Then, once an SR is calculated as a constant value for a specific kind of PAS, such a device could be used to estimate the mercury concentration in air by knowing the mass of the adsorbed analyte (i.e., the gaseous mercury), according to Equation (3):

$$
C\left(n g \cdot m^{3}\right)=\frac{\text { adorbed } \operatorname{mass}_{H g}(n g)}{\text { deployment time }(\text { day }) \cdot S R\left(m^{3} \cdot \text { day }^{-1}\right)}
$$

In the literature, depending on the range of environmental mercury concentration to be monitored, several PASs have been properly designed with different SR values [49]. PASs possessing low SRs are commonly used for long-term exposures or for high-polluted environment (e.g., for mapping wide areas or placed near factories, respectively) [59]. In these cases, the passive saturation is slowed down. For instance, Brown et al. developed PAS based on gold-coated silica placed in an axial tube without diffusive membrane possessing an SR of $0.00031 \mathrm{~m}^{3} /$ day [60], where the minimum exposure time (in low concentration environment) is $\approx 1$ year or a number of months, depending on the level of pollution. Brumbaugh et al., (2012) designed a liquid sorbent sampler containing nitric acid and gold cation surrounded by a polyethylene barrier that limits the uptake of mercury with an SR of $0.002 \mathrm{~m}^{3} /$ day, thus, the minimum exposure time is $\approx 4$ weeks if the atmosphere $\mathrm{Hg}$ concentration is higher than $2 \mathrm{ng} / \mathrm{m}^{3}$. PASs possessing high SR are used generally in an environment with a low $\mathrm{Hg}$ concentration or low exposure time: Hang et al. designed gold-coated quartz fibrous filters with an SR of $6.6 \mathrm{~m}^{3} /$ day [41]. Such devices are preferred in wearable monitoring systems and are also sensitive to small variations of $\mathrm{Hg}$ concentrations. In the present work, only the designed PAS4mg reached a constant SR of $0.01398 \mathrm{~m}^{3} /$ day $(\approx 3 \%$ uncertainty, for exposure $>7$ days), which enables the use of them in a low-polluted environment until six months, or, eventually, a highly polluted environment (e.g., workplaces) for a shorter time. However, taking into account the fact that the PAS had higher sampling rate values within the first deployment week, it is expected to be used also for shorter-term monitoring. The minimum exposure period necessary to sorb detectable amounts of $\mathrm{Hg}$ was proved to be 1 day. However, when the gaseous $\mathrm{Hg}$ concentration values were estimated from PASs exposed within 1-8 days according to Equation (1), a fair error in concentration prediction, more specifically, an overestimation, was reported if the constant SR was used for calibrating (i.e., $\approx 1.398 \times 10^{-2} \mathrm{~m}^{3} /$ day). Conversely, each predicted concentration appeared closer to the instrumental data when the PASs were calibrated with the 7-day exposure SR average (i.e., $0.018 \mathrm{~m}^{3} /$ day). In more detail, Figure 7B depicts a plot, whereas TGM concentration values from PASs working between 1 and 7 days were compared with the mean values measured over the same days by Tekran. The linear regression with intercept forced to 0 changed from $1.35 \pm 0.02\left(\left(R^{2}=0.97\right)\right.$ to $1.03 \pm 0.02\left(R^{2}=0.97\right)$ if the SR used was 
$0.018 \mathrm{~m}^{3} /$ day, thus, the data discrepancies were significantly reduced (Figure 7A,B), and the whole assessed concentrations entered within the $90 \%$ prediction band.
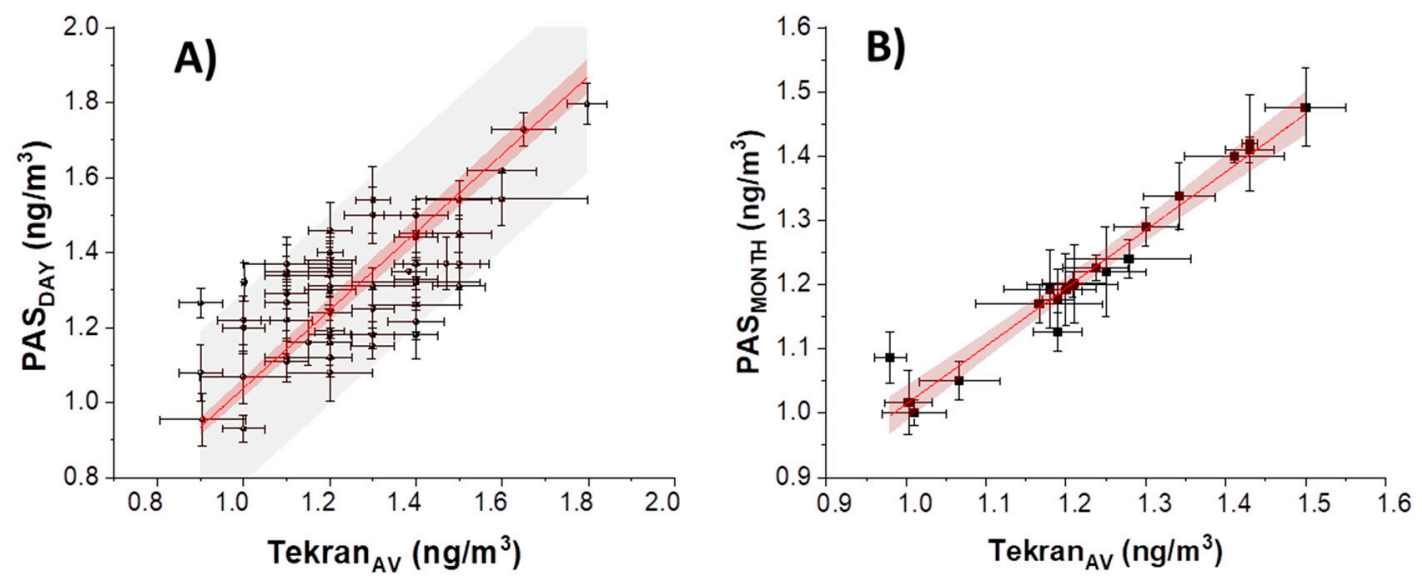

Figure 7. (A) Linear fitting of PAS data vs. Tekran collected day by day forced to pass through 0; (B) linear fitting of PAS data vs. Tekran collected monthly (SR: $0.014 \mathrm{~m}^{3} /$ day) forced to pass through 0 . The red band depicts a $95 \%$ confidence band; the gray band depicts $90 \%$ of prediction.

On the other hand, a linear correspondence between TGM concentrations from instrumental and PAS data is also depicted in Figure 7B, where measurements were related to more than 10 days of exposure (named as $\mathrm{PAS}_{\mathrm{MONTH}}$. Here, a closer relationship was observed when data obtained by Tekran were averaged and plotted against those measured through PASs, allowing us to observe overlapping between the data measured and estimated (95\% prediction band).

A passive sampler can be dependent on the meteorological factors, as well as the atmospheric mercury concentration. Therefore we tried to identify their effects on the presented PASs and on the TGM levels. Guo et al., (2014) [29] as Skov et al., (2007) [29] did not find significant effects of temperature on SR despite Gustin et al. (2011) [32] and McLagan et al. (2017) [61]. Similarly, Huang et al. (2014) observed effects of \%RH (relative humidity percentage) [27], while other studies did not report any effects on passive samplers $[29,61]$. Of course, it depended on the materials and strategies adopted to uptake mercury from air. Macagnano et al., (2018) [35], previously found a very slight relationship between the estimated mercury concentration and temperature (increasing $+0.1 \%$ per Celsius degree, in a thermal range between -20 and $\left.60{ }^{\circ} \mathrm{C}\right)$ or relative humidity levels $(+0.06 \%$ per $\%$ RH unit, between a dry and a $70 \%$ humid environment). On the other hands, both the meteorological parameters can affect the mercury distribution among the different global ecosystems (soil, water, atmosphere). Thus, in the present study, we tried to use the passive samplers as a potential tool to monitor both atmospheric TGM over 1 year, and the effects of $\mathrm{T}$ and \%RH on it. Therefore, the passive measurements were provided outdoors and were related to the meteorological parameters as temperature and relative humidity due to diurnal cycles and changing seasons. In the present study, wind effects were not considered since the selected area for PAS deployments was close to a building repairing the samplers against variations in atmospheric turbulence.

However, the opaque shield of the customized shelter (Figure 1D) protruding about $5 \mathrm{~cm}$ from the PAS entry was aimed at lowering the wind contribution; then, it was expected to be negligible. During the $\mathrm{Hg}$ monitoring campaign, $\mathrm{RH}(\%), \mathrm{T}\left({ }^{\circ} \mathrm{C}\right)$ and TGM concentrations were measured and reported as a function of the exposure period (Figure 8). During the seasons, the temperature mean values changed almost linearly from $+33^{\circ} \mathrm{C}$ to $+2{ }^{\circ} \mathrm{C}$ and back to $+35^{\circ} \mathrm{C}$ (from July to January, to the next July, respectively) (Figure 8); conversely relative humidity mean values changed from 20 to $95 \%$ (rainfalls) without definite trends related to the seasons. Looking at the concentration of mercury in the air, as expected, it was higher in the warm months [62]. 


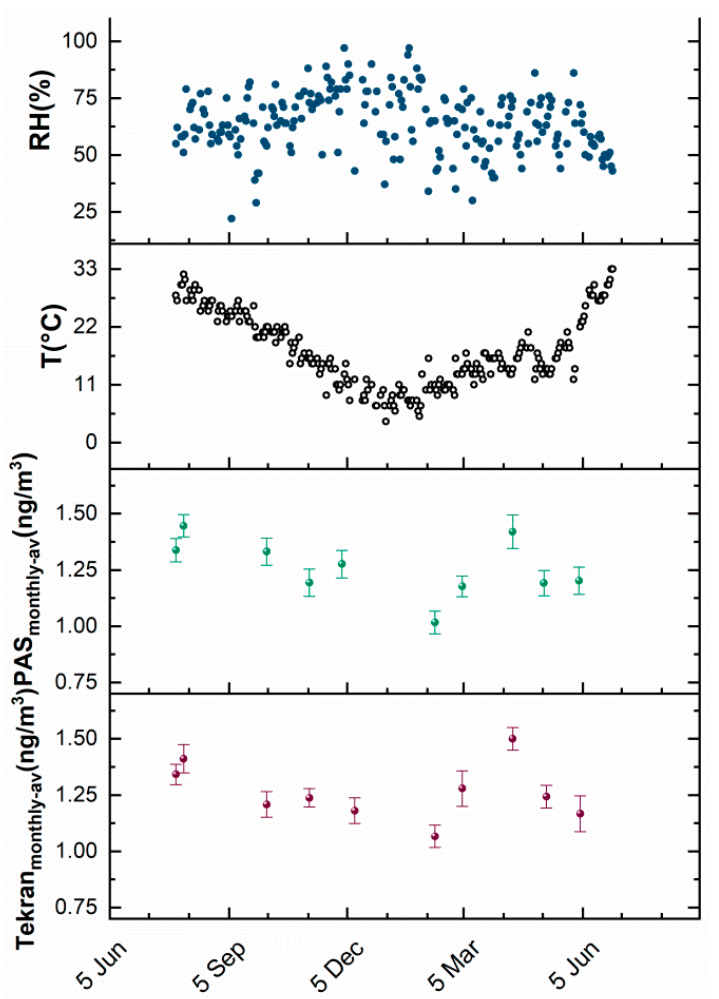

Figure 8. Composite plot depicting the daily trend of \%RH (•) and T (o) over the sampling time (1 year); averaged data from 1-month deployed PAS $(\bullet)$ and instrumental data $(\bullet)$ recorded within the same sampling time. The latter were averaged $\left(\right.$ Tekran $\left._{\text {monthly }}\right)$ to be compared to PAS values $\left(\right.$ PAS $\left._{\text {monthly }}\right)$.

Furthermore, PAS and Tekran ${ }^{\circledR}$ data seemed to report substantially similar trends and value ranges (Figure 8). Figure 9 depicts the assessed concentration of gaseous mercury versus the relative humidity (A) and temperature (B) measured over the sampling period.
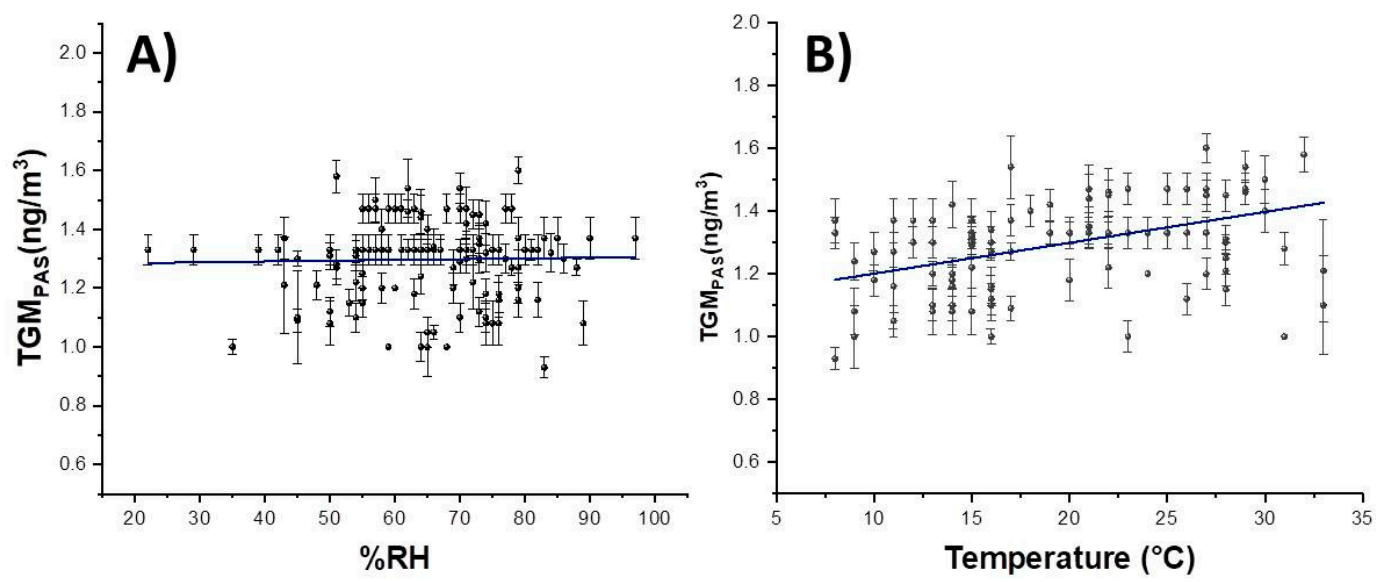

Figure 9. Linear fittings of collected data vs. \%RH (A) and T (B) values.

Each plotted value is the result of the mean of five samples working over the same days and at a defined meteorological condition. A slight relationship between mercury concentration in the air and temperature (linear regression slope of about $6.63 \pm 4.46 \mathrm{pg} / \mathrm{m}^{3} \cdot \mathrm{deg}$; intercept: $1.149 \pm 0.1256 \mathrm{ng} / \mathrm{m}^{3}$; $\left.R^{2}: 0.013\right)$. Taking into account the mean value of the gaseous concentration mercury, such a slope seems to be slightly higher $(\approx+0.6 \%$ per Celsius degree) than the rate measured in the lab $(+0.1 \%$ per Celsius degree) [35] and only due to the different interactions between the material and the mercury at different temperature values. 
Such a positive correlation is in agreement with the literature, as it had been proved that solar radiation affects the flux of mercury from the soil [62-64].

Conversely, no significant linear relationships with humidity could be observed.

\subsection{Resampling}

The ability of gold to desorb mercury at $\approx 500{ }^{\circ} \mathrm{C}$ could allow, in principle, the reusing of the adsorbing material for more measurements. Although this capacity is well known in the literature, the PAS-based resampling was conducted in only a few studies [35-38,43].

Moreover, it is known that noble metal-based PASs can undergo memory effects [49-52] and lose their structural integrity (loss of adsorbing material) [65], which can influence sampler accuracy [49].

Hence, PAS-4mgs were tested to verify the possibility of $\mathrm{Hg}$ resampling with the PASs here proposed. The weighted average of the normalized adsorbed mercury was $23 \pm 5 \mathrm{pg} /$ day, compatible with the daily values adsorbed by newly prepared membranes (Figure 10).

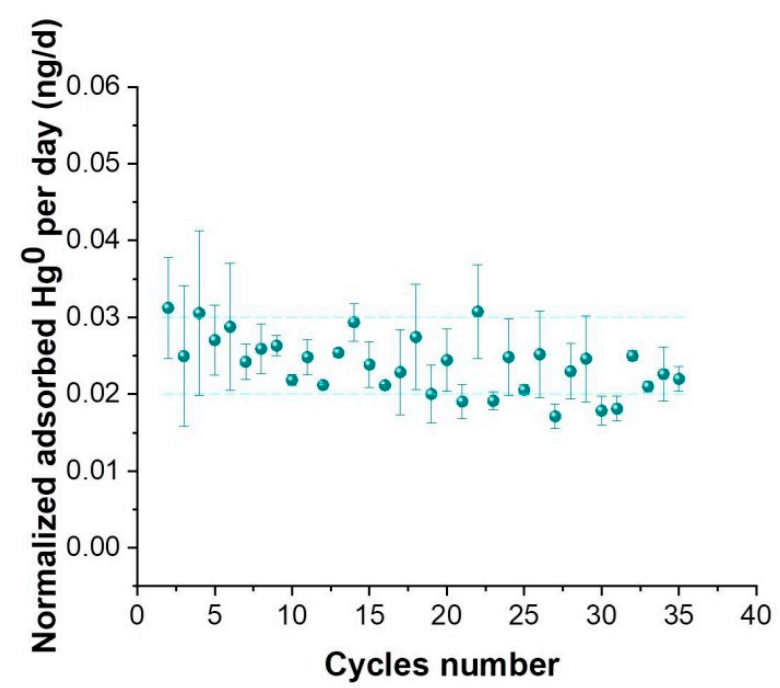

Figure 10. Normalized adsorbed mercury data as function of exposure cycles with an error bar for standard deviation.

On the other hand, the linearity of the uptake curve previously described (Figure 5) combined with the capacity of PAS to be reused in Hg resampling cycles (Figure 10), seemed to confirm the high stability of the adsorbing membranes here fabricated and used to create PASs.

\section{Conclusions}

Exploiting both the strong affinity between gold and mercury and the high surface/volume ratio, differently mass-loaded films, made of $\mathrm{TiO}_{2} \mathrm{NP}$ photo-decorated with AuNPs, were easily deposited by drop-casting onto a microfibrous filter of quartz and then investigated as promising adsorbing structures for newly designed passive samplers for gaseous mercury monitoring. The fibrous structure could hold and group the nanoparticles in microclusters over and among fibers but achieved a quite compact and stable coverage only when a $4 \mathrm{mg}$ mass was used, with a $32.6 \mu \mathrm{g} / \mathrm{mm}^{2}$ surface density. The high roughness as the high porosity, related to the irregular edges of the aggregates, improved both the adsorbing surface and the gas diffusion, affecting the mercury adsorption process. These discs, properly housed in borosilicate vessels and provided with a protective nylon membrane, were investigated as promising monitoring systems for outdoor mercury pollution in a low-contaminated site $\left(\mathrm{C}_{\mathrm{av}} \approx 1.24 \pm 0.32 \mathrm{ng} / \mathrm{m}^{3}\right)$ for up to six months. All the measurements were carried out in parallel with an analytical instrument for mercury detection (Tekran ${ }^{\circledR}$ ) and with the dual function of studying the characteristics of the material for passive sampling and validating, as a preliminary, the PAS features in the measuring campaign. The quality of the composite layer deeply affected the rate of 
TGM adsorption values that declined quickly enough over time and proportionally to the mass-loaded PASs, thus suggesting a gradual saturation of the binding sites. Over time, $\mathrm{Au} @ \mathrm{TiO}_{2} \mathrm{NPs}_{\text {were }}$ detached from filter when the coverage was not arranged in a continuous film, presumably due to weak adhesiveness of the nanoparticles to the silica scaffold. On the other hand, PAS4mg reported a linear rate of adsorption up to a hundred days, confirming the greatest stability over time as capacity of adsorption. The samplers loaded with a smaller amount of nanoparticles (comprised between 4-40 $\mu \mathrm{g}$ masses) reported a constant decline over time in the SR values without ever reaching the equilibrium, except for PAS4mg which remained stable over a longer time. Intermediate performances were observed in PAS0.4mg. These results, related to the different film framework, enhanced the need to design, for long-term monitoring systems, PASs based on $\mathrm{Au} @ \mathrm{TiO}_{2}$ nano-assembled membranes with a compact and stable architecture. In fact, PAS4mg systems worked cyclically for 1 year with continuous deployments for up to six months, providing data comparable to those achieved from an analytical instrument. The high sensitivity of the membrane also enabled the obtention of readable values from daily TGM measurements, but taking into account a proper calibration of the passive samplers in order to avoid data overestimation. Finally, the samplers were tested following 35 cycles of thermal restoration, thus confirming the keeping of their features as well as their more sustainable use. On the other hand, although the manufacturing process was reproducible, a greater control on the gold size is desired to obtain a more uniform nanocomposite architecture. Finally, all the collected data were related to a confined site, low polluted and sheltered from the wind and not subjected to the effects of salt and fine sands as well as wider thermal excursions. Each of them could considerably affect, in different ways, the features of the device. Therefore, further investigations are in progress in environments that are more polluted and in the presence of potential interferents, such as chlorides and sulfides, more windy and in extreme environmental conditions, and finally covering larger monitoring areas in order to be promoted as potential devices for global monitoring campaigns.

Supplementary Materials: The following are available online at http://www.mdpi.com/1424-8220/20/21/6021/s1, Figure S1: TEM/STEM/HRTEM TiO $@ @$ Au NPs powder characterization, Figure S2: SEM micrographs of PAS0.4mg, side views; Figure S3: SEM micrographs of PAS40 $\mu$ g, side views; Figure S4: SEM micrographs of PAS4 $\mu$ g, side views Figure S5: passive assembly procedures; Figure S6: PASs deployment.

Author Contributions: Conceptualization and design, A.M.; methodology, A.M., E.Z., A.B., F.D.C. and J.A.; validation, P.P. and J.A.; material characterization, A.M., F.D.C., M.M. and J.A.; experimental investigation, P.P., and J.A.; resources, A.M., N.P.; project administration, A.M.; data curation, J.A., P.P., F.D.C. and A.M.; writing-original draft preparation, F.D.C., J.A., A.M.; writing-review and editing, all authors; supervision, A.M. All authors have read and agreed to the published version of the manuscript.

Funding: This research was co-funded by iGOSP-ERAPLANET Project-Integrated Global Observing Systems for Persistent Pollutants (H2020-SC5-15-2015 "Strengthening the European Research Area in the domain of Earth Observation"); Type of action: ERA-NET-Cofund Grant. Grant Agreement No. 68944 (http://www.igosp.eu).

Acknowledgments: This work is part of a network of projects related to global monitoring of gaseous mercury co-funded by the Global Environment Facility (GEF), by the World Health Organization (WHO) and the Global Mercury Observation System (GMOS) and iGOSP-ERAPLANET. Authors gratefully thank A. Capocecera for his technical contribution in carrying out measurements and assembling PAS devices and A. R. Taddei from the Section of the High Equipment Centre at Tuscia University (Viterbo, Italy) for sample preparations and investigations at the Electron Microscopy.

Conflicts of Interest: The authors declare no conflict of interest.

\section{References}

1. Committee on the Toxicological Effects of Methylmercury. Toxicological Effects of Methylmercury; National Academies Press: Washington, DC, USA, 2000.

2. Global Mercury Assessment 2018|UNEP-UN Environment Programme. Available online: https://www. unenvironment.org/resources/publication/global-mercury-assessment-2018 (accessed on 22 July 2020).

3. Holmes, C.D.; Jacob, D.J.; Yang, X. Global lifetime of elemental mercury against oxidation by atomic bromine in the free troposphere. Geophys. Res. Lett. 2006, 33. [CrossRef] 
4. Lindberg, S.E.; Stratton, W.J. Atmospheric Mercury Speciation: Concentrations and Behavior of Reactive Gaseous Mercury in Ambient Air. Environ. Sci. Technol. 1998, 32, 49-57. [CrossRef]

5. $\quad$ Lindberg, S.E.; Lin, C.-J.; Scott, K.J.; Landis, M.S.; Stevens, R.K. Dynamic Oxidation of Gaseous Mercury in the Arctic Troposphere at Polar Sunrise. Environ. Sci. Technol. 2002, 36, 1245-1256. [CrossRef]

6. Lin, C.-J.; Pehkonen, S.O. The Chemistry of Atmospheric Mercury: A Review. Atmos. Environ. 1999, 33, 2067-2079. [CrossRef]

7. Duan, L.; Xiu, G.; Feng, L.; Cheng, N.; Wang, C. The mercury species and their association with carbonaceous compositions, bromine and iodine in PM2.5 in Shanghai. Chemosphere 2016. [CrossRef]

8. Han, Y.J.; Holsen, T.M.; Lai, S.O.; Hopke, P.K.; Yi, S.M.; Liu, W.; Pagano, J.; Falanga, L.; Milligan, M.; Andolina, C. Atmospheric gaseous mercury concentrations in New York State: Relationships with meteorological data and other pollutants. Atmos. Environ. 2004, 38, 6431-6466. [CrossRef]

9. Kim, M.K.; Zoh, K.D. Fate and transport of mercury in environmental media and human exposure. J. Prev. Med. Public Health 2012, 45, 335-343. [CrossRef] [PubMed]

10. Selin, N.E.; Jacob, D.J. Seasonal and spatial patterns of mercury wet deposition in the United States: Constraints on the contribution from North American anthropogenic sources. Atmos. Environ. 2008, 42, 5193-5204. [CrossRef]

11. Park, J.S.; Oh, S.; Shin, M.Y.; Kim, M.K.; Yi, S.M.; Zoh, K.D. Seasonal variation in dissolved gaseous mercury and total mercury concentrations in Juam Reservoir, Korea. Environ. Pollut. 2008, 154, 12-20. [CrossRef] [PubMed]

12. Mattoli, V.; Mazzolai, B.; Raffa, V.; Mondini, A.; Dario, P. Design of a new real-time dosimeter to monitor personal exposure to elemental gaseous mercury. Sens. Actuators B Chem. 2007, 123, 158-167. [CrossRef]

13. Kabir, K.M.M.; Ippolito, S.J.; Kandjani, A.E.; Sabri, Y.M.; Bhargava, S.K. Nano-engineered surfaces for mercury vapor sensing: Current state and future possibilities. TrAC Trends Anal. Chem. 2017, 88, 77-99. [CrossRef]

14. Salcedo, A.R.M.; Sevilla, F.B. Reversible chemiresistive sensing of ultra-low levels of elemental mercury vapor using thermally reduced graphene oxide. Microchim. Acta 2018, 185. [CrossRef] [PubMed]

15. Mercury Determination in Natural Gas, Analysis of Mercury in Natural Gas. Available online: https: //www.lumexinstruments.com/applications/mercury-determination-in-natural-gas.php (accessed on 22 July 2020).

16. Lu, J.Y.; Schroeder, W.H.; Berg, T.; Munthe, J.; Schneeberger, D.; Schaedlich, F. A Device for Sampling and Determination of Total Particulate Mercury in Ambient Air. Anal. Chem. 1998, 70, 2403-2408. [CrossRef] [PubMed]

17. Home-Tekran Instruments Corporation Tekran Instruments Corporation. Available online: https://www. tekran.com/ (accessed on 22 July 2020).

18. Driscoll, C.T.; Mason, R.P.; Chan, H.M.; Jacob, D.J.; Pirrone, N. Mercury as a global pollutant: Sources, pathways, and effects. Environ. Sci. Technol. 2013, 47, 4967-4983. [CrossRef]

19. Pandey, S.K.; Kim, K.H.; Brown, R.J.C. Measurement techniques for mercury species in ambient air. TrAC Trends Anal. Chem. 2011, 30, 899-917. [CrossRef]

20. Renner, R. EPA to strengthen persistent, bioaccumulative, and toxic pollutant controls-Mercury first to be targeted. Environ. Sci. Technol. 1999, 33, 62A. [CrossRef]

21. Margaret, A. Coulter Minamata Convention on Mercury. Int. Leg. Mater. 2016, 55, 582. [CrossRef]

22. Zhang, W.; Tong, Y.; Hu, D.; Ou, L.; Wang, X. Characterization of atmospheric mercury concentrations along an urban-rural gradient using a newly developed passive sampler-ScienceDirect. Atmos. Environ. 2012, 47, 26-32. [CrossRef]

23. McLagan, D.S.; Monaci, F.; Huang, H.; Lei, Y.D.; Mitchell, C.P.J.; Wania, F. Characterization and Quantification of Atmospheric Mercury Sources Using Passive Air Samplers. J. Geophys. Res. Atmos. 2019, 124, 2351-2362. [CrossRef]

24. Kot-Wasik, A.; Zabiegała, B.; Urbanowicz, M.; Dominiak, E.; Wasik, A.; Namieśnik, J. Advances in passive sampling in environmental studies. Anal. Chim. Acta 2007, 602, 141-163. [CrossRef]

25. Lai, F.Y.; Rauert, C.; Gobelius, L.; Ahrens, L. A critical review on passive sampling in air and water for perand polyfluoroalkyl substances (PFASs). TrAC Trends Anal. Chem. 2019, 121, 115311. [CrossRef] 
26. Król, S.; Zabiegała, B.; Namieśnik, J. Monitoring VOCs in atmospheric air II. Sample collection and preparation. TrAC Trends Anal. Chem. 2010, 29, 1101-1112. [CrossRef]

27. Huang, J.; Lyman, S.N.; Hartman, J.S.; Gustin, M.S. A review of passive sampling systems for ambient air mercury measurements. Environ. Sci. Process. Impacts 2014, 16, 374-392. [CrossRef] [PubMed]

28. McLagan, D.S.; Mitchell, C.P.J.; Huang, H.; Lei, Y.D.; Cole, A.S.; Steffen, A.; Hung, H.; Wania, F. A High-Precision Passive Air Sampler for Gaseous Mercury. Environ. Sci. Technol. Lett. 2016, 3, 24-29. [CrossRef]

29. Guo, H.; Lin, H.; Zhang, W.; Deng, C.; Wang, H.; Zhang, Q.; Shen, Y.; Wang, X. Influence of meteorological factors on the atmospheric mercury measurement by a novel passive sampler. Atmos. Environ. 2014, 97, 310-315. [CrossRef]

30. McLagan, D.; Hussain, B.; Huang, H.; Lei, Y.; Wania, F.; Mitchell, C. Identifying and evaluating urban mercury emission sources through passive sampler-based mapping of atmospheric concentrations-IOPscience. Environ. Res. Lett. 2018, 13, 074008. [CrossRef]

31. Lin, H.; Zhang, W.; Deng, C.; Tong, Y.; Zhang, Q.; Wang, X. Evaluation of passive sampling of gaseous mercury using different sorbing materials. Environ. Sci. Pollut. Res. 2017, 24, 14190-14197. [CrossRef]

32. Gustin, M.S.; Lyman, S.N.; Kilner, P.; Prestbo, E. Development of a passive sampler for gaseous mercury. Atmos. Environ. 2011, 45, 5805-5812. [CrossRef]

33. Santos, E.B.; Ferlin, S.; Fostier, A.H.; Mazali, I.O. Using gold nanoparticles as passive sampler for indoor monitoring of gaseous elemental mercury. J. Braz. Chem. Soc. 2017, 28, 1274-1280. [CrossRef]

34. De Barros Santos, E.; Moher, P.; Ferlin, S.; Fostier, A.H.; Mazali, I.O.; Telmer, K.; Brolo, A.G. Proof of concept for a passive sampler for monitoring of gaseous elemental mercury in artisanal gold mining. Sci. Rep. 2017, 7, 16513. [CrossRef]

35. Macagnano, A.; Papa, P.; Avossa, J.; Perri, V.; Marelli, M.; Sprovieri, F.; Zampetti, E.; De Cesare, F.; Bearzotti, A.; Pirrone, N. Passive sampling of gaseous elemental mercury based on a composite tio2np/aunp layer. Nanomaterials 2018, 8, 798. [CrossRef] [PubMed]

36. Papa, P.; Fratoddi, I.; Venditti, I.; Vichi, F.; Macagnano, A.; Zampetti, E.; Bearzotti, A. Use of gold nanoparticles as substrate for diffusive monitoring of gaseous mercury. Materials 2018, 11, 2119. [CrossRef] [PubMed]

37. Bearzotti, A.; Papa, P.; Macagnano, A.; Zampetti, E.; Venditti, I.; Fioravanti, R.; Fontana, L.; Matassa, R.; Familiari, G.; Fratoddi, I. Environmental $\mathrm{Hg}$ vapours adsorption and detection by using functionalized gold nanoparticles network. J. Environ. Chem. Eng. 2018, 6, 4706-4713. [CrossRef]

38. Macagnano, A.; Perri, V.; Zampetti, E.; Ferretti, A.M.; Sprovieri, F.; Pirrone, N.; Bearzotti, A.; Esposito, G.; De Cesare, F. Elemental mercury vapor chemoresistors employing $\mathrm{TIO}_{2}$ nanofibers photocatalytically decorated with Au-nanoparticles. Sens. Actuators B Chem. 2017, 247. [CrossRef]

39. Dumarey, R.; Dams, R.; Hoste, J. Comparison of the Collection and Desorption Efficiency of Activated Charcoal, Silver, and Gold for the Determination of Vapor-Phase Atmospheric Mercury. Anal. Chem. 1985, 57, 2638-2643. [CrossRef]

40. Lyman, S.N.; Gustin, M.S.; Prestbo, E.M.; Kilner, P.I.; Edgerton, E.; Hartsell, B. Testing and application of surrogate surfaces for understanding potential gaseous oxidized mercury dry deposition. Environ. Sci. Technol. 2009, 43, 6235-6241. [CrossRef] [PubMed]

41. Huang, J.; Choi, H.D.; Landis, M.S.; Holsen, T.M. An application of passive samplers to understand atmospheric mercury concentration and dry deposition spatial distributions. J. Environ. Monit. 2012, 14, 2976-2982. [CrossRef]

42. Wang, C.; Ma, L.; Hossain, M.; Wang, H.; Zou, S.; Hickman, J.J.; Su, M. Direct visualization of molecular scale chemical adsorptions on solids using plasmonic nanoparticle arrays. Sens. Actuators B Chem. 2010, 150, 667-672. [CrossRef]

43. James, J.Z.; Lucas, D.; Koshland, C.P. Gold nanoparticle films as sensitive and reusable elemental mercury sensors. Environ. Sci. Technol. 2012, 46, 9557-9562. [CrossRef]

44. McNicholas, T.P.; Zhao, K.; Yang, C.; Hernandez, S.C.; Mulchandani, A.; Myung, N.V.; Deshusses, M.A. Sensitive detection of elemental mercury vapor by gold-nanoparticle- decorated carbon nanotube sensors. J. Phys. Chem. C 2011, 115, 13927-13931. [CrossRef] [PubMed] 
45. Macagnano, A.; Perri, V.; Zampetti, E.; Bearzotti, A.; De Cesare, F.; Sprovieri, F.; Pirrone, N. A smart nanofibrous material for adsorbing and detecting elemental mercury in air. Atmos. Chem. Phys 2017, 17, 6883-6893. [CrossRef]

46. Salcedo, A.R.M.; Sevilla, F.B. Colorimetric determination of mercury vapor using smartphone camera-based imaging. Instrum. Sci. Technol. 2018, 46, 450-462. [CrossRef]

47. United States Environmental Protection Agency. EPA Method 7473 (SW-846): Mercury in Solids and Solutions by Thermal Decompostion, Amalgamation, and Atomic Absorption Spectrophotometry; United States Environmental Protection Agency: Washington, DC, USA, 2019.

48. McLagan, D.S.; Mitchell, C.P.J.; Steffen, A.; Hung, H.; Shin, C.; Stupple, G.W.; Olson, M.L.; Luke, W.T.; Kelley, P.; Howard, D.; et al. Global evaluation and calibration of a passive air sampler for gaseous mercury. Atmos. Chem. Phys. 2018, 18, 5905-5919. [CrossRef]

49. McLagan, D.S.; Mazur, M.E.E.; Mitchell, C.P.J.; Wania, F. Passive air sampling of gaseous elemental mercury: A critical review. Atmos. Chem. Phys. 2016, 16, 3061-3076. [CrossRef]

50. Ghidelli, M.; Mascaretti, L.; Bricchi, B.R.; Brognara, A.; Afifi, T.A.; Russo, V.; Casari, C.S.; Bassi, A.L. Light management in TiO2 thin films integrated with Au plasmonic nanoparticles. Semicond. Sci. Technol. 2020, 35. [CrossRef]

51. Primo, A.; Corma, A.; García, H. Titania supported gold nanoparticles as photocatalyst. Phys. Chem. Chem. Phys. 2011, 13, 886-910. [CrossRef]

52. Peeters, H.; Keulemans, M.; Nuyts, G.; Vanmeert, F.; Li, C.; Minjauw, M.; Detavernier, C.; Bals, S.; Lenaerts, S.; Verbruggen, S.W. Plasmonic gold-embedded $\mathrm{TiO}_{2}$ thin films as photocatalytic self-cleaning coatings. Appl. Catal. B Environ. 2020, 267, 118654. [CrossRef]

53. Brognara, A.; Nasri, I.F.M.A.; Bricchi, B.; Li Bassi, A.; Gauchotte-Lindsay, C.; Ghidelli, M.; Lidgi-Guigui, N. Highly sensitive detection of estradiol by a SERS sensor based on $\mathrm{TiO}_{2}$ covered with gold nanoparticles. Beilstein J. Nanotechnol. 2020, 11, 1026-1035. [CrossRef]

54. Perera, M.; Wijenayaka, L.A.; Siriwardana, K.; Dahanayake, D.; De Silva, K.M.N. Gold nanoparticle decorated titania for sustainable environmental remediation: Green synthesis, enhanced surface adsorption and synergistic photocatalysis. RSC Adv. 2020, 10, 29594-29602. [CrossRef]

55. Brosset, C.; Iverfeldt, Å. Interaction of solid gold with mercury in ambient air. Water. Air. Soil Pollut. 1989, 43, 147-168. [CrossRef]

56. Barghigiani, C.; Ristori, T.; Cortopassi, M. Air mercury measurement and interference of atmospheric contaminants with gold traps. Environ. Technol. (UK) 1991, 12, 935-941. [CrossRef]

57. Jeon, J.-W.; Han, Y.-J.; Cha, S.-H.; Kim, P.-R.; Kim, Y.-H.; Kim, H.; Seok, G.-S.; Noh, S. Application of the Passive Sampler Developed for Atmospheric Mercury and Its Limitation. Atmosphere 2019, 10, 678. [CrossRef]

58. Zhang, X.; Wania, F. Modeling the uptake of semivolatile organic compounds by passive air samplers: Importance of mass transfer processes within the porous sampling media. Environ. Sci. Technol. 2012, 46, 9563-9570. [CrossRef] [PubMed]

59. Brumbaugh, W.G.; Petty, J.D.; May, T.W.; Huckins, J.N. A passive integrative sampler for mercury vapor in air and neutral mercury species in water. Chemosph. Glob. Chang. Sci. 2000, 2, 1-9. [CrossRef]

60. Brown, R.J.C.; Burdon, M.K.; Brown, A.S.; Kim, K.H. Assessment of pumped mercury vapour adsorption tubes as passive samplers using a micro-exposure chamber. J. Environ. Monit. 2012, 14, 2456-2463. [CrossRef]

61. McLagan, D.S.; Mitchell, C.P.J.; Huang, H.; Hussain, B.A.; Lei, Y.D.; Wania, F. The effects of meteorological parameters and diffusive barrier reuse on the sampling rate of a passive air sampler for gaseous mercury. Atmos. Meas. Tech. 2017, 10, 3651-3660. [CrossRef]

62. Hu, Q.H.; Kang, H.; Li, Z.; Wang, Y.S.; Ye, P.P.; Zhang, L.; Yu, J.; Yu, X.W.; Sun, C.; Xie, Z.Q. Characterization of atmospheric mercury at a suburban site of central China from wintertime to springtime. Atmos. Pollut. Res. 2014, 5, 769-778. [CrossRef]

63. Moore, C.; Carpi, A. Mechanisms of the emission of mercury from soil: Role of UV radiation. J. Geophys. Res. 2005, 110, D24302. [CrossRef] 
64. Schlüter, K. Review: Evaporation of mercury from soils. An integration and synthesis of current knowledge. Environ. Geol. 2000, 39, 249-271. [CrossRef]

65. Brown, R.J.C.; Kumar, Y.; Brown, A.S.; Kim, K.H. Memory effects on adsorption tubes for mercury vapor measurement in ambient air: Elucidation, quantification, and strategies for mitigation of analytical bias. Environ. Sci. Technol. 2011, 45, 7812-7818. [CrossRef]

Publisher's Note: MDPI stays neutral with regard to jurisdictional claims in published maps and institutional affiliations.

(C) 2020 by the authors. Licensee MDPI, Basel, Switzerland. This article is an open access article distributed under the terms and conditions of the Creative Commons Attribution (CC BY) license (http://creativecommons.org/licenses/by/4.0/). 